\title{
Lacrimal Gland Amyloidosis in an Elderly Patient
}

\author{
Toshiya Nagai Tatsuya Yunoki Atsushi Hayashi \\ Department of Ophthalmology, Graduate School of Medicine and Pharmaceutical \\ Sciences, University of Toyama, Toyama, Japan
}

\section{Keywords}

Lacrimal gland · Localized amyloidosis · Transthyretin

\begin{abstract}
Localized amyloidosis of the lacrimal gland is a rare disease. We report a case of transthyretinpositive localized amyloidosis of the lacrimal gland in a 74-year-old man with left lacrimal gland swelling. Biopsy of the left lacrimal gland showed extensive deposition of nonstructural eosinophilic material in the secretory gland and ducts, which stained positive with direct fast scarlet. Immunostaining was negative for amyloid A and positive for both globulin light chain (kappa, lambda) and transthyretin. It is necessary to consider the possibility of senile systemic amyloidosis, even if localized amyloidosis of the lacrimal gland is suspected.
\end{abstract}

(C) 2019 The Author(s)

Published by S. Karger AG, Basel

\section{Introduction}

Amyloidosis causes functional and morphological impairment due to the extracellular deposition of amyloid protein in various organs. Amyloidosis can be classified into systemic amyloidosis, in which amyloid is deposited in the tissues and organs, and localized amyloidosis, in which amyloid deposition is localized [1]. Periocular amyloidosis is reported to be localized to the eyelids, cornea, and conjunctiva [2]. There have been several reports of amyloidosis of the lacrimal gland in the literature, although it is a relatively rare condition [3-8].

\section{KARGER}


Herein, we report a case of transthyretin-positive amyloidosis localized to the lacrimal gland, which was diagnosed by a biopsy of the lacrimal gland mass.

\section{Case Report}

A 74-year-old man was diagnosed with sarcoidosis uveitis at another hospital in July 2015 and was prescribed steroid eye drop therapy. Swelling of the lacrimal gland was observed in June 2018, and the patient was referred to our hospital for detailed examination (Fig. 1). The best-corrected decimal visual acuity was 0.8 and 1.0 in the right and left eyes, respectively. The right eye showed opaque media, which was a nuclear cataract. Pseudophakia was observed in the left eye. Although there were no inflammatory cells in the anterior and vitreous chambers, mild retinal vasculitis and mild epi-retinal membrane were observed on fluorescein fundus angiography. Uveitis caused by sarcoidosis was thought to be relatively controlled. Lacrimal gland biopsy was performed because of the possibility that the left lacrimal gland swelling was caused by sarcoid granuloma. The biopsy revealed extensive deposition of nonstructural eosinophilic material in the secretory gland and ducts, which was direct fast scarlet positive. Immunostaining was negative for amyloid A and positive for globulin light chains (kappa and lambda) (Fig. 2). Orbital magnetic resonance imaging and thoracoabdominal computed tomography revealed no other lesions. Hence, a diagnosis of primary localized lacrimal gland light chain (AL) amyloidosis was made. However, additional immunostaining revealed transthyretin positivity (Fig. 3). Electrocardiography and echocardiography did not reveal any obvious heart disease. Clinically, primary localized lacrimal gland amyloidosis was suspected. Since the specimen was positive for transthyretin, the possibility of senile systemic amyloidosis was also taken into consideration, and the patient is currently being followed up.

\section{Discussion}

The eyelid, cornea, and conjunctiva are the common sites for localized amyloidosis of the eye, while the lacrimal gland is relatively rarely involved [3-8]. The patient described in this report was being treated for sarcoidosis uveitis. Since there have been reports of lacrimal amyloidosis complicated by systemic diseases such as Sjögren's syndrome, sarcoidosis, and multiple myeloma $[9,10]$, the possibility of systemic amyloidosis was also considered. Several studies have reported that amyloidosis can be complicated by sarcoidosis [11-16]. However, this patient tested negative for amyloid $A$ and positive for globulin light chain, and thus, a diagnosis of localized AL amyloidosis of the lacrimal gland was made. Moreover, according to earlier reports, most cases of ocular appendage amyloidosis are characterized by the deposition of AL type amyloid protein $[2,17,18]$. However, additional immunostaining confirmed the presence of transthyretin. Wild-type transthyretin deposits are observed in the cardiac tissue of elderly patients with senile systemic amyloidosis, in whom it is an important cause of heart failure and arrhythmia [19]. Senile systemic amyloidosis is often asymptomatic, and autopsy studies have shown that $20-30 \%$ of patients above the age of 80 years have senile systemic amyloidosis [20,21]. Lacrimal gland biopsy revealed transthyretin-positive amyloidosis in this patient. Although cardiac symptoms, which are the principal symptoms, were not observed, the possibility of senile systemic amyloidosis with lacrimal gland lesions cannot be denied, since it is often asymptomatic. However, there have been no reports of AL amyloidosis 
concomitant with transthyretin-positive amyloidosis as seen in this case, which was extremely challenging to diagnose.

Earlier reports have shown that there may be cases where immunostaining may provide false-positive results for transthyretin, rendering the immunohistological classification of amyloidosis difficult [22]. Furthermore, the possibility of false positive results cannot be denied in this case. However, since there have been no reports of false-positive results for transthyretin lacrimal gland amyloidosis, the possibility of senile systemic amyloidosis should be considered, and systemic examination seems essential.

Since the visual function is apparently unaffected by amyloidosis at present, the patient is being followed up without treatment for amyloidosis. There is no consensus regarding the treatment of localized lacrimal gland amyloidosis that causes no abnormality in visual function. Visual acuity and optic nerve disorders are considered to be less serious complications of periocular amyloidosis. However, it can result in considerable ocular morbidity, such as eye movement disorders and blepharoptosis [4, 23]. Surgical excision and radiation therapy are the treatment options if the ocular symptoms become prominent [4]. Thus, we thought that it was necessary to perform careful follow-up, taking into consideration the possibility of the systemic and ocular symptoms of transthyretin-positive lacrimal gland amyloidosis. Continued follow-up should include electrocardiography and echocardiography, while considering the possibility of heart disease.

\section{Acknowledgments}

The authors wish to thank Dr. Noriko Okuno and Dr. Masakiyo Sasahara of the University of Toyama for the pathological diagnosis.

\section{Statements of Ethics}

The patient described in this case report provided informed consent for its publication, and the procedures conformed to the tenets of the World Medical Association's Declaration of Helsinki.

\section{Disclosure Statement}

The authors declare that they have no conflicts of interest.

\section{Funding Sources}

The authors received no funding sources. 


\section{Author Contributions}

T.Y. and T.N. drafted the manuscript and collected the data. M.S. made the pathological diagnosis. T.Y. and A.H. reviewed the final version of the manuscript. All authors have read and approved the final manuscript.

\section{References}

1 Real de Asúa D, Costa R, Galván JM, Filigheddu MT, Trujillo D, Cadiñanos J. Systemic AA amyloidosis: epidemiology, diagnosis, and management. Clin Epidemiol. 2014 Oct;6:369-77.

2 Blandford AD, Yordi S, Kapoor S, Yeaney G, Cotta CV, Valent J, et al. Ocular Adnexal Amyloidosis: A Mass Spectrometric Analysis. Am J Ophthalmol. 2018 Sep;193:28-32.

3 Conlon MR, Chapman WB, Burt WL, Larocque BJ, Hearn SA. Primary localized amyloidosis of the lacrimal glands. Ophthalmology. 1991 Oct;98(10):1556-9.

4 Leibovitch I, Selva D, Goldberg RA, Sullivan TJ, Saeed P, Davis G, et al. Periocular and orbital amyloidosis: clinical characteristics, management, and outcome. Ophthalmology. 2006 Sep;113(9):1657-64.

5 Al Hussain H, Edward DP. Anterior orbit and adnexal amyloidosis. Middle East Afr J Ophthalmol. 2013 JulSep;20(3):193-7.

6 Cheng JY, Fong KS, Cheah ES, Choo CT. Lacrimal gland amyloidosis. Ophthal Plast Reconstr Surg. 2006 JulAug;22(4):306-8.

7 Batra J, Ali MJ, Mody K, Naik MN, Vemuganti GK. Lacrimal gland amyloidosis: a clinicopathological correlation of a rare disorder and review of literature. Ocul Immunol Inflamm. 2014 Aug;22(4):300-5.

8 Prabhakaran VC, Babu K, Mahadevan A, Murthy SR. Amyloidosis of lacrimal gland. Indian J Ophthalmol. 2009 Nov-Dec;57(6):461-3.

9 Kweon SM, Koh JH, Lee HN, Kim E, So MW, Shin HJ, et al. Primary Sjogren syndrome diagnosed simultaneously with localized amyloidosis of the lacrimal gland: A case report. Medicine (Baltimore). 2018 Jun;97(23):e11014.

10 Brown G, Shapeero LG, Weiss BM, Roschewski M. Multiple myeloma with lacrimal gland amyloidosis and sarcoidosis. Am J Hematol. 2010 Jul;85(7):506-9.

11 Stather D, Ford S, Kisilevsky R. Sarcoid, amyloid, and acute myocardial failure. Mod Pathol. 1998 Sep;11(9):901-4.

12 Carreiro M, Margarit-Coll N, Sailler L, Roussel C, Dahan S, Uro-Coste E, et al. [Localized amyloidosis of the bladder and sarcoidosis: analysis of a fortuitous association]. Rev Med Interne. 2002 Jul;23(7):668-9. French.

13 Komatsuda A, Wakui H, Ohtani H, Maki N, Nimura T, Takatsu H, et al. Amyloid A-type renal amyloidosis in a patient with sarcoidosis: report of a case and review of the literature. Clin Nephrol. 2003 Oct;60(4):284-8.

14 Treaba DO, Benson MD, Assad LW, Dainauskas JR. Sarcoidosis and immunoglobulin lambda II light-chain amyloidosis diagnosed after orthotopic heart transplantation: a case report and review of the literature. Mod Pathol. 2005 Mar;18(3):451-5.

15 Nakai N, Ozawa A, Katoh N. Nodular primary localized cutaneous amyloidosis in a patient with pulmonary sarcoidosis. Indian J Dermatol. 2014 May;59(3):307-8.

16 Schade L, Carmes ER, de Barros JA. Mediastinal lymph node amyloidosis in a patient with sarcoidosis. J Bras Pneumol. 2007 Mar-Apr;33(2):222-5.

17 Mora-Horna ER, Rojas-Padilla R, López VG, Guzmán MJ, Ceriotto A, Salcedo G. Ocular adnexal and orbital amyloidosis: a case series and literature review. Int Ophthalmol. 2016 Apr;36(2):281-98.

18 Eneh AA, Farmer J, Kratky V. Primary localized orbital amyloid: case report and literature review; $2004-$ 2015. Can J Ophthalmol. 2016 Aug;51(4):e131-6.

19 Hattori T, Takei Y, Koyama J, Nakazato M, Ikeda S. Clinical and pathological studies of cardiac amyloidosis in transthyretin type familial amyloid polyneuropathy. Amyloid. 2003 Dec;10(4):229-39.

20 Cornwell GG 3rd, Murdoch WL, Kyle RA, Westermark P, Pitkänen P. Frequency and distribution of senile cardiovascular amyloid. A clinicopathologic correlation. Am J Med. 1983 Oct;75(4):618-23.

21 Yazaki M, Higuchi K. [Senile systemic amyloidosis]. Brain Nerve. 2014 Jul;66(7):817-26. Japanese.

22 Gustavsson A, Engström U, Westermark P. Mechanisms of transthyretin amyloidogenesis. Antigenic mapping of transthyretin purified from plasma and amyloid fibrils and within in situ tissue localizations. Am J Pathol. 1994 Jun;144(6):1301-11.

23 Massry GG, Harrison W, Hornblass A. Clinical and computed tomographic characteristics of amyloid tumor of the lacrimal gland. Ophthalmology. 1996 Aug;103(8):1233-6. 


\section{Case Reports in Ophthalmology}

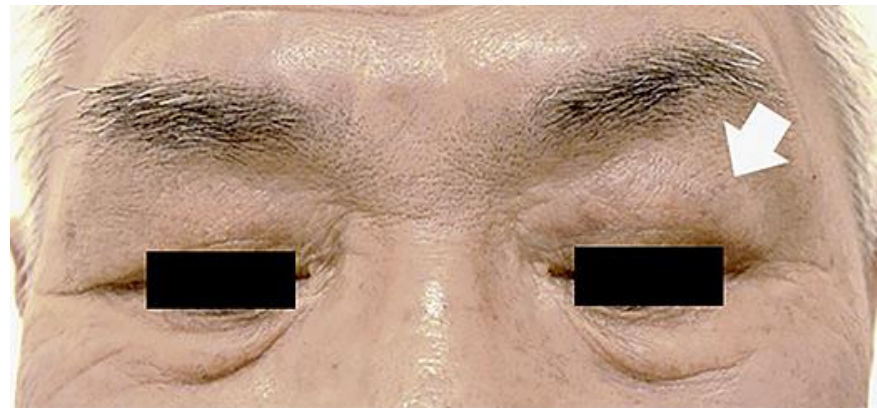

Fig. 1. Photograph showing the swelling of the left lacrimal gland (white arrow).
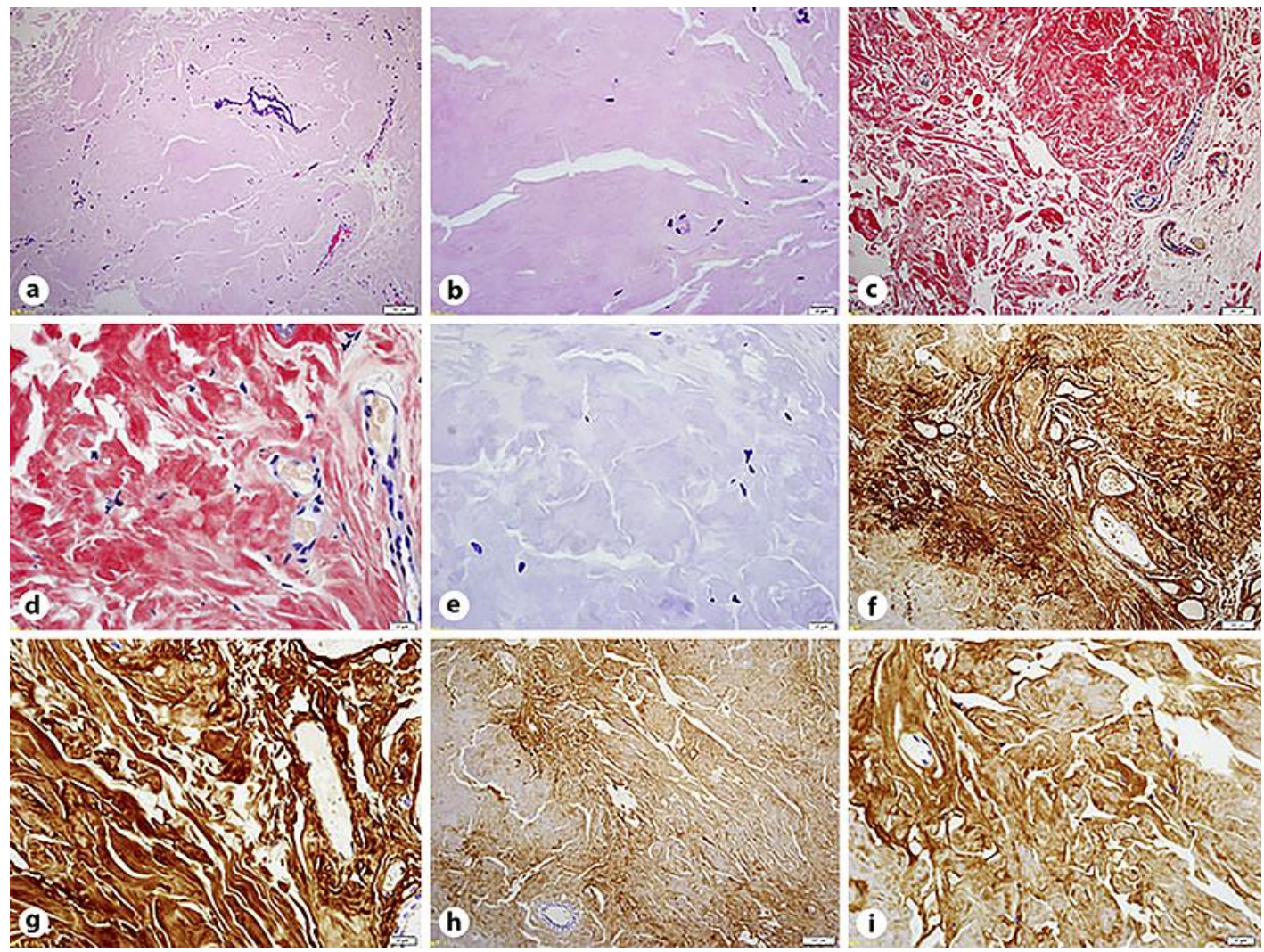

Fig. 2. Pathological examination and tissue immunostaining of the left lacrimal gland biopsy showing (a original magnification $\times 10$, $\mathbf{b}$ original magnification $\times 40$ ) extensive deposition of nonstructural eosinophilic material in the secretory gland and ducts (coriginal magnification $\times 10$, d original magnification $\times 40$ ), which was direct fast scarlet (DFS) positive (e original magnification $\times 40$ ), amyloid A negative (f original magnification $\times 10$, g original magnification $\times 40$ ), globulin light chain (kappa) positive (h original magnification $\times 10$, i original magnification $\times 40$ ), and globulin light chain (lambda) positive. 


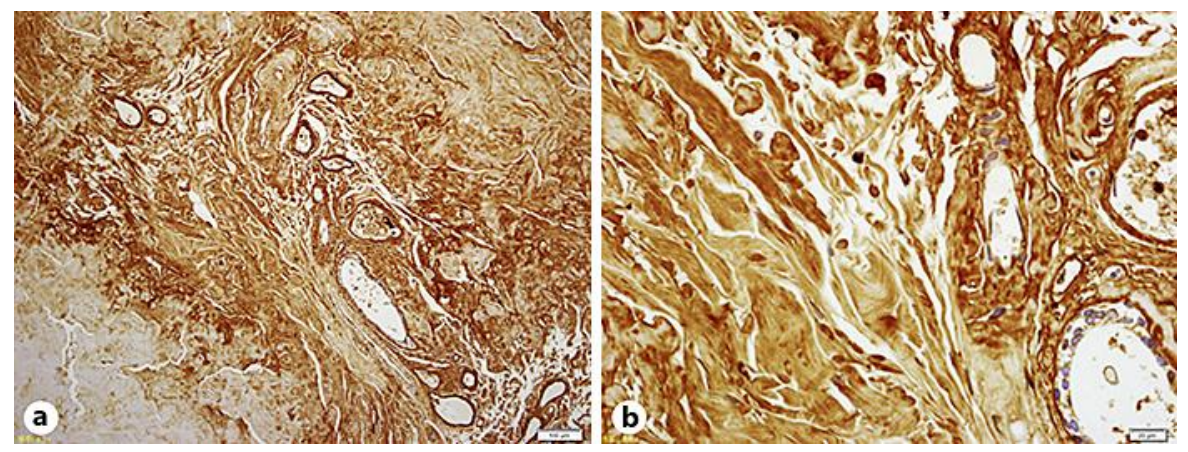

Fig. 3. Tissue immunostaining of the biopsy specimen of the left lacrimal gland showing transthyretin positivity (a original magnification $\times 10$, b original magnification $\times 40$ ). 